\title{
Gestational Diabetes Mellitus (GDM) - Diagnosis, Treatment and Follow-Up. Guideline of the DDG and DGGG (S3 Level, AWMF Registry Number 057/008, February 2018)
}

\author{
Gestationsdiabetes mellitus (GDM) - Diagnostik, Therapie \\ und Nachsorge. Leitlinie der DDG und DGGG \\ (S3-Niveau, AWMF-Registernummer 057/008, Februar 2018)
}

\section{(ㄷ)(1) (옹 $\Theta$}

Authors

Ute Margaretha Schäfer-Graf ${ }^{1}$, Ulrich Gembruch ${ }^{2}$, Franz Kainer ${ }^{3}$, Tanja Groten ${ }^{4}$, Sandra Hummel ${ }^{5}$, Irene Hösli ${ }^{6}$, Mellita Grieshop ${ }^{7}$, Matthias Kaltheuner ${ }^{8}$, Christoph Bührer ${ }^{9}$, Alexandra Kautzky-Willer ${ }^{10}$, Katharina Laubner ${ }^{11}$, Dagmar Bancher-Todesca ${ }^{12}$

\author{
Affiliations \\ 1 Perinatalzentrum, Klinik für Gynäkologie und Geburtshilfe, \\ Berlin, Germany \\ 2 Obstetrics \& Prenatal Medicine, Universitätsklinikum Bonn, \\ Bonn, Germany \\ 3 Geburtshilfe und Pränatalmedizin, Klinik Hallerwiese, \\ Nürnberg, Germany \\ 4 Klinik für Frauenheilkunde und Geburtshilfe, Universitäts- \\ klinikum Jena, Jena, Germany \\ 5 Diabetes, Helmholtz Zentrum München Deutsches \\ Forschungszentrum für Umwelt und Gesundheit, \\ Neuherberg, Germany \\ 6 Obstetrics, University Hospital, Basel, Switzerland \\ 7 Hebammenstudiengang, Evangelische Hochschule Berlin, \\ Berlin, Germany \\ 8 Diabetesschwerpunktpraxis, Leverkusen, Germany \\ 9 Neonatologie, Charite, Berlin, Germany \\ 10 Med. Universität Vienna, Wien, Austria \\ 11 Diabetes, Universität Freiburg, Freiburg, Germany \\ 12 Gynäkologie und Geburtshilfe, Universität Wien, Wien, \\ Austria
}

Key words

gestational diabetes, obstetrics, diabetes mellitus, pregnancy

Schlüsselwörter

Gestationsdiabetes, Geburtshilfe, Diabetes mellitus,

Schwangerschaft

received 30.4 .2018

revised 28.6.2018

accepted 16.7.2018
Bibliography

DOI https://doi.org/10.1055/a-0659-2596

Geburtsh Frauenheilk 2018; 78: 1219-1231 @ Georg Thieme

Verlag KG Stuttgart · New York | ISSN 0016-5751

Correspondence

Prof. Dr. Ute Schaefer-Graf

Berliner Diabeteszentrum für Schwangere, Klinik für

Gynäkologie und Geburtshilfe, St. Joseph Krankenhaus

Wüsthoffstraße 15, 12101 Berlin, Germany

ute.schaefer-graf@sjk.de

(日)

Deutsche Version unter:

https://doi.org/10.1055/a-0659-2596

\section{ABSTRACT}

A team of experts from the fields of gynaecology and obstetrics, diabetology, internal medicine, paediatrics and midwifery from Germany, Austria and Switzerland produced a new version of the existing $\mathbf{S 3}$ guideline on gestational diabetes. It replaces the recommendations of the German Association for Gynaecology and Obstetrics and the German Diabetes Association on the diagnosis and treatment of gestational diabetes from 2011 and is valid for the three German-speaking countries. The primary aim of the guideline is to improve and standardise the prevention, screening, diagnosis, treatment and follow-up of gestational diabetes through evidence-based recommendations for the outpatient and inpatient area. A large number of new studies and data published in the last few years required a comprehensive revision of the 2011 guideline. The new aspects include early screening of pregnant women with a high risk for diabetes or gestational diabetes, the validity of two-stage screening in the third trimester by means of the 50 - $\mathrm{g}$ challenge test, as specified in the maternity guidelines, use of metformin instead of or in addition to 
insulin in gestational diabetes, and birth planning with GDM and/or macrosomia. The recommendations are based on the evidence from the literature, which was selected through a systematic external literature search. All recommendations had to pass through a consensus process. The present text corresponds to the practice guideline on gestational diabetes, which is an action-oriented short version of the evidencebased $\mathrm{S} 3$ guideline that can be viewed on the internet.

\section{ZUSAMMENFASSUNG}

Ein Expertenteam aus dem Bereich der Gynäkologie und Geburtshilfe, Diabetologie, Innere Medizin, Kinderheilkunde und Hebammenwissenschaften aus Deutschland, Österreich und Schweiz erstellte eine neue Version der bestehenden S3Leitlinie zum Gestationsdiabetes. Sie ersetzt die Empfehlungen der Deutschen Gesellschaft für Gynäkologie und Geburtshilfe und der Deutschen Diabetesgesellschaft zur Diagnostik und Therapie des Gestationsdiabetes aus dem Jahr 2011 und ist für die 3 deutschsprachigen Länder gültig. Primäres Ziel der Leitlinie ist die Verbesserung und Vereinheitlichung von
Prävention, Screening, Diagnostik, Therapie und Nachsorge bei Gestationsdiabetes durch evidenzbasierte Empfehlungen für den ambulanten und stationären Bereich. Eine Vielzahl von Veröffentlichungen neuer Studien und Daten der letzten Jahre erforderte eine umfassende Überarbeitung der Leitlinie von 2011. Die neuen Aspekte betreffen u. a. das Frühscreening bei Schwangeren mit hohem Risiko für Diabetes oder Gestationsdiabetes, die Validität des 2-stufigen Screenings im 3. Trimenon mittels 50 -g-Suchtest, wie es in den Mutterschaftsrichtlinien vorgeschrieben ist, die Gabe von Metformin statt oder in Ergänzung zu Insulin bei Gestationsdiabetes und die Geburtsplanung bei GDM und/oder Makrosomie. Die Empfehlungen basieren auf der Evidenz, die sich aus der Literatur ergibt, deren Auswahl über eine systematische, externe Literatursuche erfolgte. Alle Empfehlungen mussten einen Konsensus-Prozess durchlaufen. Der vorliegende Text entspricht der Praxisleitlinie zum Gestationsdiabetes, die eine handlungsorientierte Kurzfassung der im Internet einsehbaren evidenzbasierten S3-Leitlinie ist.

\section{Guideline Information}

\section{Guideline program of the DGGG, OEGGG and SGGG}

Information at the end of the article.

\section{Citation format}

Gestational Diabetes Mellitus (GDM), Diagnosis, Treatment and Follow-Up. Guideline of the DDG and DGGG (S3 Level, AWMF Registry Number 057/008, February 2018). Geburtsh Frauenheilk 2018; 78: 1219-1231

\section{Guideline documents}

The complete long version with a list of the conflicts of interest of all the authors, a power point version, a patient version and other documents can be viewed on the AWMF homepage:

http://www.awmf.org/guidelinen/detail/I/057-008.html

\section{Guideline group ( $>$ Table 1 )}

\footnotetext{
> Table 1 Guideline group.

Coordinator

- Prof. Dr. Ute Schäfer-Graf, Berlin

Experts appointed by the DDG

- Dr. Katharina Laubner, Freiburg

- PD Dr. Sandra Hummel, München

Experts appointed by the DGGG

- Prof. Dr. Ulrich Gembruch, Bonn
}

- Table 1 Guideline group. (Continued)

Other specialist societies/groups involved and appointed experts (incl. Austria and Switzerland)

Gynaecology and obstetrics area

- Arbeitsgemeinschaft für Materno-Fetale Medizin (AGMFM) [Maternofoetal medicine working group]/Arbeitsgemeinschaft für Geburtshilfe und Pränatalmedizin [Obstetrics and prenatal medicine working group] (AGG) of the DGGG: PD Dr. Tanja Groten, Jena

- Deutsche Gesellschaft für Perinatale Medizin (DGPM) [German perinatal medicine association]/Deutsche Gesellschaft für Pränatal- und Geburtsmedizin (DGPGM) [German prenatal and obstetric medicine association]: Prof. Dr. Franz Kainer, Nürnberg

- Deutsche Gesellschaft für Hebammenwissenschaften (DGHWi) [German midwifery science association]: Prof. Dr. rer. medic. Melita Grieshop, Berlin

- Österreichische Gesellschaft für Gynäkologie und Geburtshilfe (ÖGGG) [Austrian gynaecology and obstetrics association]: Prof. Dr. Dagmar Bancher-Todesca, Vienna; Prof. Dr. Mila Cervar-Zivakovic, Graz

- Schweizerische Gesellschaft für Gynäkologie und Geburtshilfe (SGGG) [Swiss gynaecology and obstetrics association]: Prof. Dr. Irene Hösli, Basel

Diabetology and internal medicine area

- DiabetesDE: Dr. Matthias Kaltheuner, Leverkusen

- Deutsche Gesellschaft für Innere Medizin (DGIM) [German internal medicine sssociation]: Dr. Gellner, Münster (only consensus conference)

- Österreichische Diabetes Gesellschaft (ÖDG) [Austrian diabetes association]: Prof. Dr. Alexandra Kautzky-Willer, Wien

- Schweizerischen Gesellschaft für Endokrinologie und Diabetologie (SGED) [Swiss endocrinology and diabetology association]: Prof. Dr. Michael Brändle (not actively involved)

Neonatology area

- Gesellschaft für Neonatologie und pädiatrische Intensivmedizin (GNPI) [Neonatology and paediatric intensive medicine association]: Prof. Dr. Christoph Bührer, Berlin; Prof. Segerer, Regensburg

Methodical processing (literature search and evaluation)

- Dr. Patchev, formerly Institute for Clinical Studies, University of Jena 


\section{Abbreviations}

ACE Angiotensin Converting Enzyme

ACOG American College of Obstetricians and Gynecologists

ACHOIS Australian Carbohydrate Intolerance Study in Pregnant Women

AWMF Arbeitsgemeinschaft der Wissenschaftlichen Medizinischen Fachgesellschaften [Working group of scientific medical specialist associations]

AC-HC Ratio of abdominal circumference to head circumference

AUC Area Under the Curve

BG Blood Glucose

BQS Bundesgeschäftsstelle für Qualitätssicherung [German Federal Office for Quality Assurance]

BMI Body Mass Index

CGMS Continuous Glucose Monitoring System

CSII Continuous subcutaneous insulin infusion (insulin pump)

CTG Cardiotocography

DDG Deutsche Diabetes Gesellschaft [German Diabetes Association]

DEGUM Deutsche Gesellschaft für Ultraschall in der Medizin [German Association for Ultrasound in Medicine]

DGGG Deutsche Gesellschaft für Gynäkologie und Geburtshilfe [German Gynaecology and Obstetrics Association]

EPDS Edinburgh Postnatal Depression Scale

EDD Estimated Date of Delivery

FPG Fasting Plasma Glucose

GAD Glutamate Decarboxylase

GCK Glucokinase

GCT Glucose Challenge Test

GDM Gestational Diabetes

GI Glycaemic Index

HAPO Hyperglycemia and Adverse Pregnancy Outcomes

HELLP Hemolysis, Elevated Liver Enzymes, Low Platelets (HELLP is a complication of pre-eclampsia associated with this symptom combination)

IA2 Thyrosine Phosphatase (IA = islet antigen)

IADPSG International Association of Diabetes in Pregnancy Study Groups

ICA Islet Cell Autoantibodies

ICT Intensified Conventional Insulin Therapy (with multiple injections and separation of basal insulin and mealtime insulin)

IFG Impaired Fasting Glucose

IGT Impaired Glucose Tolerance

IOM Institute of Medicine

IQWiG Institut für Qualität und Wirtschaftlichkeit im Gesundheitswesen [Institute for Quality and Efficiency in Health Care]

IUD Intrauterine Death

IUGR Intrauterine Growth Reduction

CHO Carbohydrates

LGA Large for Gestational Age (above the 90th percentile for gestational age and sex)

\section{Macrosomia}

Birth Weight over 4000 gramm

MBG Mean Blood Glucose

MODY Maturity Onset Diabetes in the Young

NDDG National Diabetes Data Group

NICE National Institute for Health and Clinical Excellence

NGT Normal Glucose Tolerance

NT Nuchal Transparency

oGTT Oral Glucose Tolerance Test

PCOS Polycystic ovarian syndrome

POCT Point of Care Testing

RCT Randomised Controlled Study

RiLiBÄK Richtlinie der Bundesärztekammer zur Qualitätssicherung labormedizinischer Untersuchungen [Guideline of the German Medical Association on quality assurance of medical laboratory examinations]

RR Relative risk is the comparison of two risks, risk = percentage of cases with target event out of the totality of all cases with and without the target event

SGA Small for Gestational Age (below the 10th percentile for gestational age and sex)

Unit Use Laboratory reagent packaged for single measurement and used once

\section{Guideline Application}

\section{Questions and aims}

The aim of this guideline is to improve and standardise the prevention, screening, diagnosis, treatment and follow-up of gestational diabetes through evidence-based recommendations.

\section{Care area}

Outpatient and inpatient area

\section{Target patient group}

The target patient group is pregnant women with gestational diabetes or increased risk for diabetes.

\section{Target user group/audience}

The target group addressed by the guideline consists of specialists in gynaecology and obstetrics, internal and general medicine, diabetologists, midwives and neonatologists. In addition, the guideline provides information for groups of persons involved in care such as dieticians, psychologists and other groups involved in the health of pregnancy women.

\section{Adoption and period of validity}

This guideline has a period of validity from 28.02.2018 until 27.02.2023. This period is estimated based on its content. If there are important changes in the evidence, amendments to the guideline will be published through the AWMF before the expiry of this period following methodological assurance. 


\section{Guideline}

\section{Definition}

Gestational diabetes mellitus (GDM, ICD-10: O24.4G) is defined as an impairment of glucose tolerance that is diagnosed for the first time in pregnancy with a 75-g oral glucose tolerance test (oGTT) under standardised conditions and with quality-assured glucose measurement from venous plasma. Diagnosis is also possible when the glucose level is elevated. The definition of overt diabetes corresponds to that outside pregnancy; it does not belong to the GDM category but is termed "Diabetes diagnosed in pregnancy".

\section{Pathophysiology}

The pathophysiology of GDM largely corresponds to that of type 2 diabetes. GDM is a variant of pre-type 2 diabetes and can today be described as a chronic dysfunction characterised by increasing insulin resistance with diminishing $\beta$ cell compensation. Unfavourable pregnancy outcomes in women with GDM can be mitigated or prevented by timely diagnosis and intensive treatment.

\section{Epidemiology}

In Germany, the GDM prevalence in the perinatal statistics was $5.38 \%$ (41000 cases) in the year 2016 and was therefore increasing by $14.6 \%$ compared with 2015 .

\section{Prevention}

There have been numerous studies of lifestyle changes for prevention of GDM (change of diet, increased physical activity, taking supplements such as myoinositol, vitamin D, probiotics, fish oil) without clear results. Weight reduction through a healthy lifestyle should be recommended to women who are overweight and obese when they are planning pregnancy. This should be maintained during pregnancy.

\section{Consequences for mother and child}

Acute consequences for the mother

There are increased risks for urinary tract and vaginal infections, with an increased rate of premature delivery as a result, for pregnancy-induced hypertension, pre-eclampsia, delivery by caesarean section, shoulder dystocia, higher-grade birth injuries, postpartum haemorrhage requiring transfusion and depression. Preconception obesity $\left(\mathrm{BMI}>30 \mathrm{~kg} / \mathrm{m}^{2}\right.$ ) per se leads more often to section and macrosomic babies, independent of GDM.

Long-term consequences for the mother

\section{Diabetes risk in later life}

After GDM, 35-60\% of women develop diabetes (risk increased 7to 8-fold compared with glucose-tolerant pregnant women) within 10 years. Even in the first year after the pregnancy, roughly $20 \%$ of European women have various forms of impaired glucose metabolism. The risk of conversion to overt diabetes is increased in women who are obese before conception, Asian women, GDM diagnosis $<24$ weeks of gestation, insulin therapy, 1-h oGTT $\geq 200 \mathrm{mg} / \mathrm{dl}(11.1 \mathrm{mmol} / \mathrm{l})$ in pregnancy, $\mathrm{HbA}_{1 \mathrm{c}} \geq 5.7 \%$ at GDM diagnosis. The incidence of type 1 diabetes is $2.3-10 \%$ in risk groups 5-10 years after GDM.

\section{Cardiovascular risk profile}

Women have a higher risk of developing metabolic syndrome after GDM. This is associated with a higher risk for cardiovascular disease (coronary heart disease with myocardial infarction, coronary bypass, coronary angioplasty/stenting, stroke, PAD), even at a young age.

\section{Risk of recurrence of GDM}

Women of Caucasian origin: 35-50\% risk of recurrence of GDM in subsequent pregnancies. Risk factors: obesity $\left(\mathrm{BMl}>30 \mathrm{~kg} / \mathrm{m}^{2}\right)$, number of pregnancies, GDM diagnosis before 24 weeks of gestation in previous pregnancies, insulin therapy, interval of $<24$ months between the pregnancies, weight gain of more than $3 \mathrm{~kg}$ between the pregnancies, raised fasting blood glucose two months post partum. In ethnic groups with a high diabetes risk (Asia, Latin America), the subsequent risk rises to $50-84 \%$.

\section{Acute consequences for the child}

The increased intrauterine glucose supply leads to increased foetal insulin secretion (foetal hyperinsulinism), deposition of glycogen in cardiac muscle, production of white fat and reduced foetal surfactant production. The foetal haematocrit increases as a result of a raised intrauterine erythropoietin level. Diabetic foetopathy is apparent at birth to a variable degree, with hypoglycaemia, respiratory disorders, polycythaemia, hypocalcaemia, hypomagnesaemia and hyperbilirubinaemia.

\section{Long-term consequences for the child}

While it is unclear whether GDM as such is associated with longterm metabolic sequelae for a child, factors associated with GDM in particular (maternal and also paternal obesity, family diet and exercise habits) increase the long-term risk for childhood obesity and the development of impaired glucose tolerance. Interventions during pregnancy to reduce elevated glucose levels alone do not suffice to prevent later obesity in the child. Postnatal measures in the form of lifestyle optimisation (breast-feeding, type of infant and toddler nutrition, early promotion of exercise) must follow.

\section{Screening and diagnosis}

Screening on first attendance in pregnancy

when there is a risk for diabetes

Pregnant women with increased risk ( $\triangleright$ Table 2) should be screened for the presence of impaired glucose tolerance or preexisting (hitherto unrecognised) diabetes mellitus (type 1 or 2) when they first attend in early pregnancy (before 24 weeks). If there are specific symptoms of diabetes (polyuria, polydipsia, pronounced glycosuria in spot urine), patients should be screened for diabetes mellitus undiagnosed prior to conception. Please refer to the joint, annually updated recommendations on diagnosis of diabetes mellitus of the Laboratory diagnostics in diabetology committee of the German Diabetes Association (DDG) and the German Clinical Chemistry and Laboratory Medicine Association (DGKL) (see DDG homepage). 


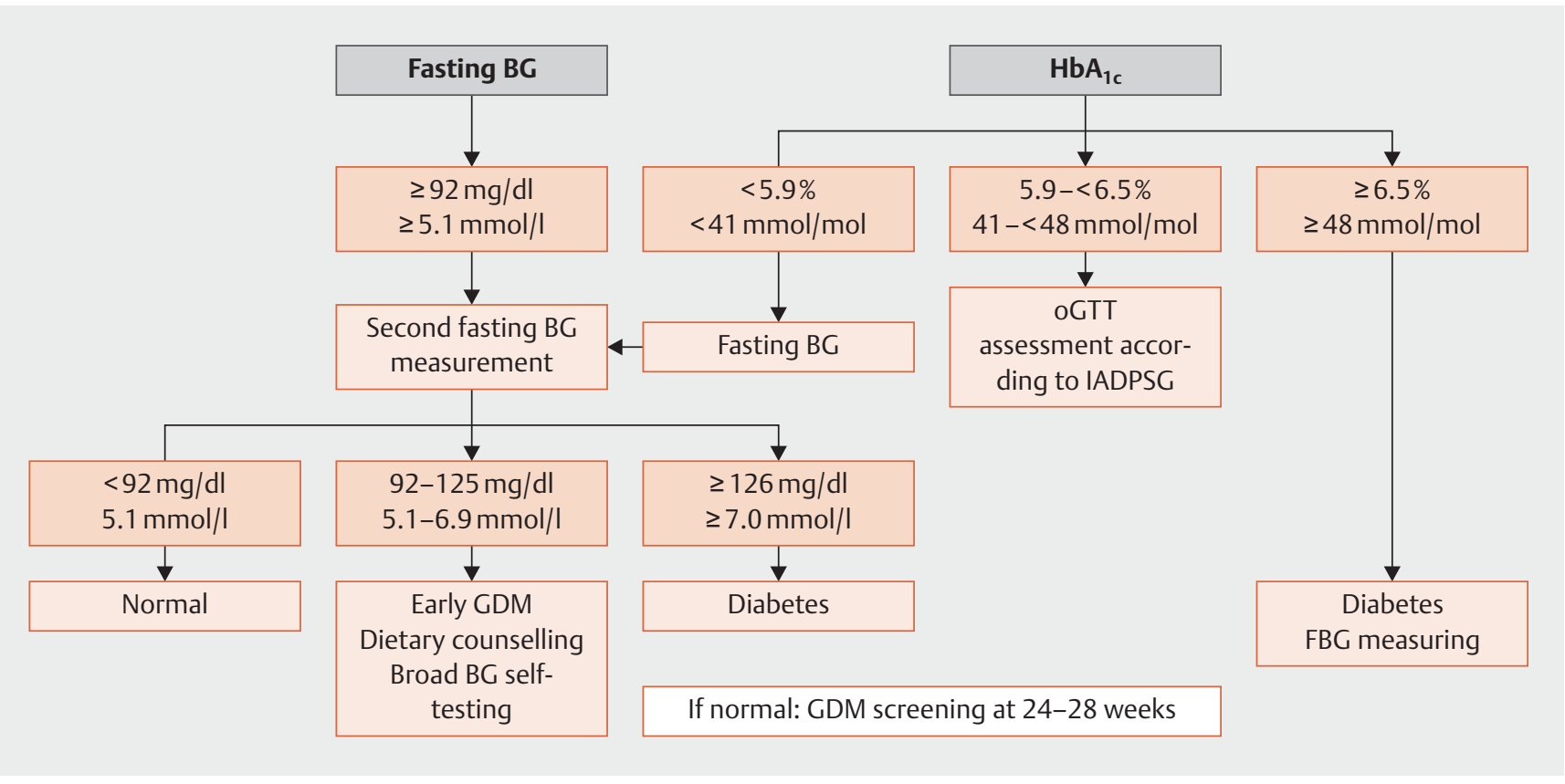

- Fig. 1 Diabetes screening in early pregnancy when there is a risk for $\mathrm{DM}\left(\mathrm{HbA}_{1 \mathrm{c}}\right)$ or $\mathrm{GDM}\left(\mathrm{HbA}_{1 \mathrm{c}}\right)$. [rerif]

Two methods are possible ( $\bullet$ Fig. $\mathbf{1}$ ):

- Measurement of fasting glucose. Diabetes mellitus and gestational diabetes (GDM) are ruled out when the blood glucose level in venous plasma is $\leq 92 \mathrm{mg} / \mathrm{dl}(5.1 \mathrm{mmol} / \mathrm{l})$. A second measurement is done when the blood glucose level in venous plasma is $\geq 92 \mathrm{mg} / \mathrm{dl}(5.1 \mathrm{mmol} / \mathrm{l})$. This must be done on a different day. The blood glucose measurements must meet laboratory standards. The result of the second measurement is decisive, and measurements must be above the threshold or the diagnosis cannot be made. At blood glucose levels of 92$125 \mathrm{mg} / \mathrm{dl}$ (5.1-6.9 mmol/l), GDM in early pregnancy is present according to the IAPDSG and WHO. Dietary counselling and blood glucose self-measurement are recommended. Diabetes mellitus (probably "pre-conception") is present at plasma glucose levels $\geq 126 \mathrm{mg} / \mathrm{dL}(7.0 \mathrm{mmol} / \mathrm{L})$.

- Measurement of $\mathrm{HbA}_{1 \mathrm{c}}$ level. Diabetes mellitus but not previous GDM is excluded at a $\mathrm{HbA}_{1 \mathrm{c}}$ level of $\leq 5.9 \%$ so measurement of fasting blood glucose is necessary in addition. At $\mathrm{HbA}_{1 \mathrm{c}}$ levels of 5.9-6.4\%, an oGTT is recommended for further investigation, with assessment according to the IADPSG and WHO. Diabetes is confirmed at levels $\geq 6.5 \%$.

When screening is negative in early pregnancy, regular GDM screening takes place at $24+0-27+6$ weeks according to maternity guidelines, preferably by $75-\mathrm{g}$ oGTT ( $\bullet$ Fig. 1 ).

Screening for GDM at $24+0$ to $27+6$ weeks

According to the available evidence, a 75-g oGTT should be performed between $24+0-27+6$ weeks of gestation in all pregnant women to screen for GDM, preferably as a one-stage procedure ( $\triangleright$ Fig. 3).
- Table 2 Independent risk factors for development of GDM in the course of pregnancy.

\begin{tabular}{|c|c|c|}
\hline & OR & $95 \% \mathrm{Cl}$ \\
\hline \multicolumn{3}{|l|}{ Pregnancy with previous GDM } \\
\hline - Previous GDM & 50.4 & $42.1-60.3$ \\
\hline - Weight (> $69 \mathrm{~kg}$ ) & 1.02 & $1.01-1.03$ \\
\hline \multicolumn{3}{|l|}{ Pregnancy without previous GDM } \\
\hline - No GDM in previous pregnancy & 0.45 & $0.4-0.5$ \\
\hline - Age (compared with 35 years) & 1.08 & $1.07-1.09$ \\
\hline - Weight (>69 kg) & 1.03 & $1.03-1.04$ \\
\hline - Height (> 1.64 m) & 0.94 & $0.93-0.95$ \\
\hline - 1 st degree relative with diabetes & 2.5 & $2.2-2.8$ \\
\hline - 2nd degree relative with diabetes & 1.7 & $1.4-2.1$ \\
\hline - Ovulation induction & 1.6 & $1.1-2.3$ \\
\hline - East Asian origin & 2.9 & $2.2-3.8$ \\
\hline - South Asian origin & 2.3 & $1.8-2.8$ \\
\hline $\begin{array}{l}\text { - Birth weight Z score of previous } \\
\text { children }\end{array}$ & 1.25 & $1.1-1.3$ \\
\hline
\end{tabular}

According to the German maternity guidelines, screening for GDM should be performed initially by a 50 -g GCT (glucose challenge test) ( $\bullet$ Fig. 2). The 50 -g GCT is performed non-fasting independent of the time of day and food intake. The patient drinks $50 \mathrm{~g}$ glucose in $200 \mathrm{ml}$ water. A blood glucose level in venous plas$\mathrm{ma} \geq 135 \mathrm{mg} / \mathrm{dl}(7.5 \mathrm{mmol} / \mathrm{l})$ after one hour is regarded as positive screening and requires a subsequent diagnostic 75-g oGTT. 


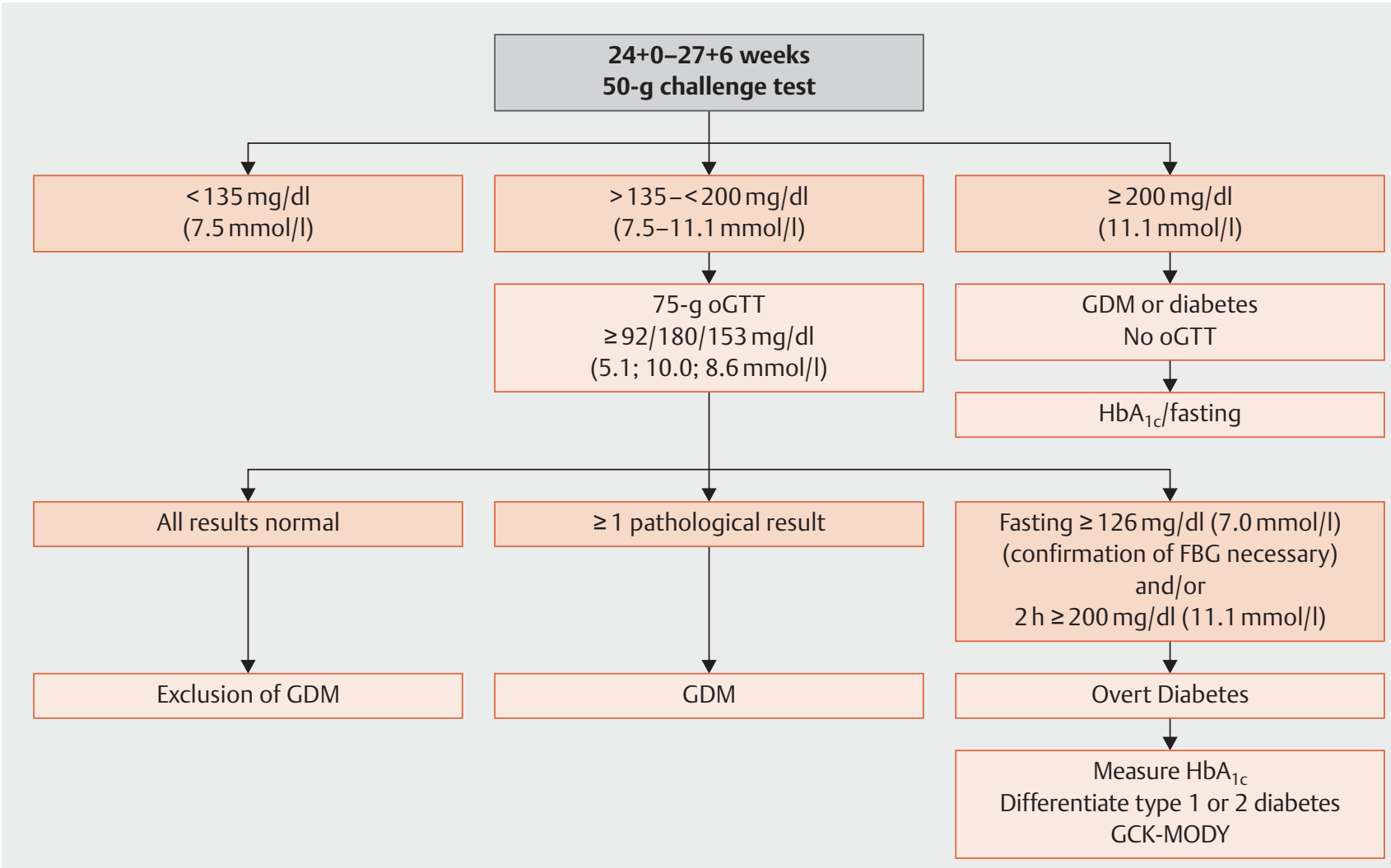

- Fig. 2 Screening for gestational diabetes in the 3rd trimester according to German maternity guidelines. [rerif]

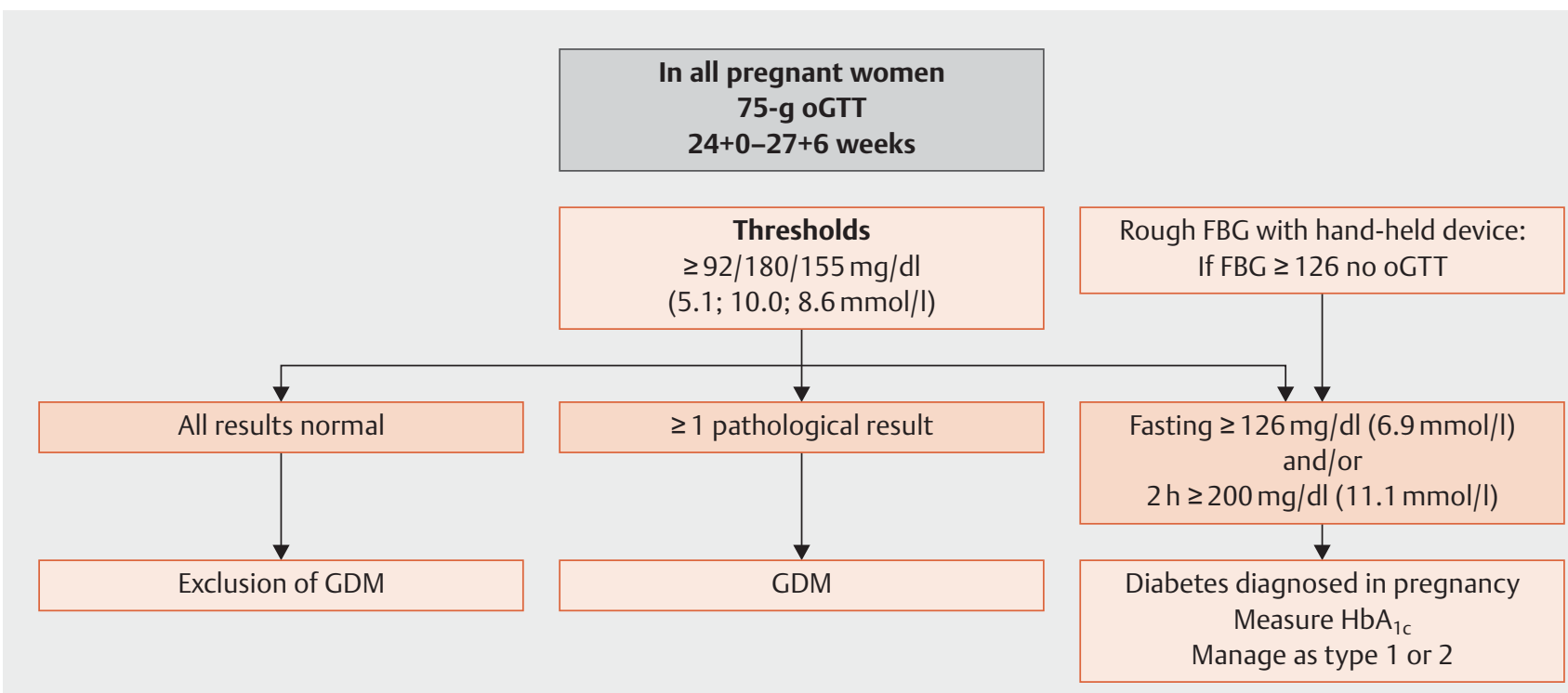

- Fig. 3 Evidence-based screening and diagnostic procedure. [rerif] 
GDM is diagnosed at a blood glucose level in venous plasma $\geq 200 \mathrm{mg} / \mathrm{dl}(11.2 \mathrm{mmol} / \mathrm{l})$ and the $75-\mathrm{g}$ oGTT is unnecessary.

According to the HAPO study, elevation of the fasting level only was present in $33 \%$ of women with GDM, and this is not detected by the $50-\mathrm{g}$ GCT. Since the fasting level has the closest correlation with unfavourable pregnancy outcome, however, measurement of the fasting blood glucose in addition is recommended if the 50-g GCT betweeen $24+0$ and $27+6$ weeks is negative. This does not form part of the maternity guidelines.

GDM screening methods such as urine glucose, fasting glucose, random glucose or $\mathrm{HbA}_{1 c}$ are not recommended here; screening by fasting glucose is established in Switzerland ( Fig. 2).

\section{Diagnosis of GDM by 75-g oGTT}

The 75-g oGTT is performed fasting in the morning under standard conditions. If the stipulated time window $(24+0$ weeks and $27+6$ weeks) is exceeded, the test can also be performed later at the HCP's discretion. If there are signs suggesting GDM (polyhydramnios, macrosomia with $\mathrm{AC}>\mathrm{HC}$ or massive glycosuria), repeated testing for GDM with a diagnostic 75-g oGTT directly is indicated in the 3rd trimester also if screening at 24-28 weeks was negative.

The standard conditions include:

- No acute disease/fever/hyperemesis/medically prescribed bedrest.

- No ingestion or parenteral administration of contra-insulin medication in the morning before the test (e.g., cortisol, L-thyroxine, $\beta$-mimetics, progesterone). After induction of foetal lung maturity with betamethasone because of threatened premature delivery, at least 5 days must elapse after the last injection and the pregnant woman must be at least partially mobilised before the oGTT is started.

- No previous operation on the upper gastrointestinal tract (e.g., bariatric surgery with an ablative/malabsorptive procedure) Alternative: single blood glucose measurements, especially fasting.

- No unusual physical exercise before the test.

- Normal, individual eating and drinking with the usual amount of carbohydrates in the last 3 days before the test (the pregnant woman must not prepare for the test by changing her diet, especially by leaving out carbohydrates).

- Observation of a fasting period of at least 8 hours in the night before the test from 22:00 h.

- The test starts the next morning, not before 6:00 h and not after 9:00 h (glucose tolerance depends on the time of day).

- During the test, the pregnant woman should sit near the test laboratory and not move unnecessarily.

- No smoking before and during the test.

Immediately before the start of the test, the venous fasting plasma glucose is measured. The pregnant woman then sips $75 \mathrm{~g}$ anhydrous glucose dissolved in $300 \mathrm{ml}$ water or a similar oligosaccharide mixture within 3-5 min. Further glucose measurements: one and two hours after finishing drinking the glucose solution.
If there is severe nausea or vomiting of pregnancy, the test must be postponed by a few days.

\section{Threshold 75-g oGTT results}

The IADPSG criteria are used as standard diagnostic thresholds according to the maternity guidelines. GDM is diagnosed when at least one of the three threshold levels in venous plasma are reached or exceeded ( $\vee$ Table 3 ).

A fasting blood glucose level $\geq 126 \mathrm{mg} / \mathrm{dl}(7.0 \mathrm{mmol} / \mathrm{l})$ is regarded at this time as probable overt diabetes mellitus. Confirmation by a second fasting blood glucose measurement on a different day and by $\mathrm{HbA}_{1 \mathrm{c}}$ is indicated. The diagnosis of overt diabetes mellitus is confirmed or excluded by the second blood glucose measurement; both results must be $\geq 126 \mathrm{mg} / \mathrm{dl}$. The $75-\mathrm{g}$ oGTT must not be continued if overt diabetes mellitus is confirmed by two fasting blood glucose levels $\geq 126 \mathrm{mg} / \mathrm{dl}$.

A level $\geq 200 \mathrm{mg} / \mathrm{dl}(11.1 \mathrm{mmol} / \mathrm{l})$ two hours after exercise also allows the diagnosis of diabetes mellitus. Additional $\mathrm{HbA}_{1 \mathrm{c}}$ measurement is then appropriate. Further care is then as for known type 1 or type 2 diabetes pre-conception.

If the oGTT is limited to one hour (measurement fasting and after one hour), $2.1 \%$ of all pregnant women with GDM will not be detected according to HAPO.

\section{Blood samples and measurement quality requirements}

For GDM diagnosis, blood glucose levels are measured exclusively in venous plasma directly, or in venous whole blood and converted to venous plasma levels by a factor of $1.11(+11 \%)$ or a plasmacalibrated measuring system is used. Hand-held devices for measuring capillary blood glucose should be rejected. Conversion of capillary levels to venous levels is impermissible. Blood glucose measurements to diagnose GDM must meet the quality requirements of the German Medical Council guideline (RiLiBÄK). When unit-use reagents and corresponding measuring systems are used for initial diagnosis of overt diabetes in pregnancy or gestational diabetes, like all other glucose measuring systems, these should be designed expressly according to the manufacturer's recommendations for medical diagnostic use. When used in a doctor's office, external quality assurance according to RiLiBÄK rules should be performed.

- Table 3 Threshold levels in venous plasma according to IADPSG consensus recommendations.

\begin{tabular}{|l|l|c|}
\hline $\begin{array}{l}\text { Time } \\
\mathbf{2 4}+\mathbf{0}-\mathbf{2 7}+\mathbf{6}\end{array}$ & $\begin{array}{l}\text { Threshold levels } \\
\text { weeks of gestation }\end{array}$ & $\begin{array}{l}\text { IADPSG } \\
\text { venous plasma }\end{array}$ \\
\hline & $\mathbf{m g} / \mathbf{d l}$ & $\mathbf{m m o l} / \mathbf{l}$ \\
\hline Fasting & 92 & 5.1 \\
\hline After 1 hour & 180 & 10.0 \\
\hline After 2 hours & 153 & 8.5 \\
\hline
\end{tabular}


For detailed information on preanalytics, methodology and evaluation in the determination of plasma glucose and $\mathrm{HbA}_{1 \mathrm{c}}$, please refer to the practical guide „Definition, classification and diagnosis of diabetes mellitus" of the DDG ${ }^{*}$.

\section{Blood glucose measurement: errors, confounding factors}

Venous whole blood or plasma measurements can be incorrect especially as a result of different, preanalytic procedures. The main problem is insufficient preanalytic inhibition of glycolysis when the sample is sent. From practical considerations, glucose from a venous whole blood sample should be measured immediately with a point-of-care system approved for diagnosis using a RiliBÄK quality-assured measurement method (converted to plasma equivalent with the factor $1.11[+11 \%]$ or an appropriately plasma-calibrated device should be used; the sample tube must contain an anticoagulant). When sending venous whole blood samples, the sample tube should contain the immediately acting glycolysis inhibitor citrate/citrate buffer as well as an anticoagulant and NaF. To obtain valid results, the manufacturer's instructions should be followed when filling the tubes.

\section{Diagnosis of GDM after bariatric surgery}

After surgical procedures that affect absorption, GDM diagnosis is not possible by an oral glucose tolerance test (dumping phenomenon). To investigate hyperglycaemia that requires treatment, monitoring of fasting and 1-hour postprandial blood glucose levels is therefore recommended (2-hour levels are not reliable) by obtaining blood glucose day profiles for 2 weeks under normal dietary conditions, for example at 12, 24 and 32 weeks of gestation, with appropriate diabetology care if the target levels are exceeded. To date, there are no studies of this procedure.

\section{Treatment}

\section{First medical consultation after GDM diagnosis}

This should be a detailed discussion in a calming atmosphere. The pregnant woman is confronted for the first time with the concept of "diabetes". Depending on the needs of migrant or illiterate women, the presence of an interpreter or companion must be ensured so that the planned measures are understood and can be implemented. If the pregnant woman is classified as incapable of giving consent, the discussion and treatment should be postponed.

The elements of the structured first medical consultation include:

- Significance of the diagnosis for the child and the mother;

- Timeframe of the measures to be initiated and the care structure;

\footnotetext{
Deutsche Diabetes Gesellschaft (DDG); Deutsche Vereinte Gesellschaft für Klinische Chemie und Laboratoriumsmedizin (DGKL). Definition, Klassifikation und Diagnostik des Diabetes mellitus. 2016. Online: www. deutsche-diabetes-gesellschaft.de/fileadmin/Redakteur/Leitlinien/ Praxisleitlinien/2016/dus_2016_S2_Supplement_Praxisempfehlungen_ M\%C3\%BCller-Wieland_Definition_Klassifikation_und_Diagnostik_ des_DM_Online-PDF.pdf; last access: 13.11.2017
}

- Explanation that treatment will usually be outpatient-based;

- Importance of blood glucose self-monitoring;

- Need for possible dietary modification and the target weight development according to Institute of Medicine recommendations;

- Advantages of regular exercise (increase insulin sensitivity);

- Reasons for possible use of pharmacological therapy with insulin or metformin as off-label use;

- Open-ended conclusion of the consultation with questions about worries and fears.

Physical activity

Regular physical exercise, fitness programmes or sport reduce the risk for GDM, especially in women who are obese pre-conception, and improve the capacity to cope with pregnancy and delivery. Moreover, the risk for LGA and caesarean section is reduced, as is the need for insulin treatment or the daily insulin dose requirement. Sport can be continued during pregnancy; individual advice from the gynaecologist is required and the contraindications must be noted. Endurance or strength training at a low to moderate level can also be started during pregnancy. The simplest type of physical exercise without aids should be brisk walking for at least 30 min at least 3 times a week or daily exercise with an elastic strap. Physical activity/training should start pre-conception or in the first trimester. Short exercise units in the first postprandial hour after main meals are beneficial.

\section{Dietary counselling}

The first treatment measure is individual dietary evaluation and counselling. This should be based on communicating the principles of a balanced healthy diet for pregnant women. The "Healthy start in life" network has developed an appropriate template (Federal Centre for Nutrition (BZfE) of the Federal Office for Agriculture and Food (BLE), www.gesund-ins-leben.de/inhalt/handlungsempfehlungen-29378.html). This takes into account eating habits, daily rhythms, body weight and sociocultural religious status to achieve the following treatment goals:

- normal, pregnancy-specific blood glucose target levels without ketosis and hypoglycaemic episodes;

- the maternal weight gain recommended for pregnancy;

- normal growth of the foetus.

The diet should be adjusted to the nutritional requirements in pregnancy and provide sufficient calories. Recommended nutrient distribution:

- Carbohydrates: 40-50\%;

- Protein: $20 \%$;

- Fat: $30-35 \%$.

Limiting $\mathrm{CHO}$ to $40-45 \%$ of daily energy calories reduces postprandial blood glucose levels. The $\mathrm{CHO}$ percentage should not be less than $40 \%$ or $175 \mathrm{~g} /$ day, however. Carbohydrates with a high fibre content and low glycaemic index should be preferred. It is recommended to divide the $\mathrm{CHO}$ over the day between three not too large main meals and 2-3 smaller snacks (including a late meal), and in this way, insulin therapy may be avoided. There is no evidence for this from RCTs. The volume of carbohydrate 
should be lower at breakfast than at lunch and dinner (highest blood glucose increase). A late meal containing 1 unit of $\mathrm{CHO}$ prevents excess ketone body production during the night. An adequate supply of vitamins and minerals (folic acid, vitamin B complex, calcium, vitamin D, magnesium, iron, iodine) should be ensured. Energy-free sweeteners (e.g., aspartame) can be used in pregnancy, observing the acceptable daily dosages.

\section{Recommended weight gain}

Weight gain likewise is guided by the pre-conception BMI. Weight gain within IOM limits is desirable. Weight loss of $1-2 \mathrm{~kg}$ in the first weeks after a change of diet can occur and is harmless. Glucose metabolism is improved and insulin sensitivity is increased by controlled weight loss. Increased pre-conception BMI and exceeding the stated weight limits increases the rate of pregnancy complications (pre-eclampsia, section, SGA and LGA babies). Lower weight gain than recommended increases the rate of foetal growth retardation. In obese women, lower weight gain $(0-5 \mathrm{~kg}$ total weight gain) is harmless. Pregnant women should check their weight weekly at home in the morning fasting and without clothes and record it ( $\vee$ Table 4 ).

\section{Blood glucose monitoring}

\section{Blood glucose single measurements}

Measurement frequency at the start: 4-point profile for $1-2$ weeks - fasting in the morning and 1 or 2 hours after the start of the main meals. If all results within the first 2 weeks are in the target range, the test frequency is then reduced to a single daily measurement in rotation or a 4-point profile twice a week. Additional targeted measurements are possible as stipulated by the HCP. Insulin therapy: daily measurements with 4-point profile or only daily monitoring of the level that is to be optimised by insulin therapy. The frequency and timing of self-testing are individually adjusted continually depending on the complexity and progress of therapy and according to the obtained results. The priority is to minimise the burden on the pregnant woman and limit self-testing to the minimum required for decision-making. Like the accuracy of the blood glucose hand-held test system (monitoring of the monitoring system), the pregnant woman's blood glucose self-testing (monitoring of self-monitoring) should be checked regularly. Pregnant women with GDM are given suitable diaries for documentation and they are shown how to record results correctly.

\section{Continuous glucose monitoring system (CGMS)}

CGMS is not part of the routine care of pregnant women with GDM and does not lead to an improvement in pregnancy outcome.

$\mathrm{HbA}_{1 \mathrm{c}}$

As part of early screening ( $\leq 24$ weeks), the $\mathrm{HbA}_{1 \mathrm{c}}$ level is used to diagnose a pre-existing disorder of glucose metabolism or overt diabetes mellitus (see section on "Screening on first attendance in pregnancy"). After confirmed diagnosis of GDM, the $\mathrm{HbA}_{1 \mathrm{c}}$ is measured only when diabetes mellitus (type 1 or 2 ) is suspected. $\mathrm{HbA}_{1 \mathrm{c}}$ is of no significance in monitoring the treatment and control of gestational diabetes, but it can be a helpful additional pa-
- Table 4 Recommended weight gain range during pregnancy.

\begin{tabular}{|c|c|c|}
\hline $\begin{array}{l}\text { Pre-conception } \\
\mathrm{BMI}\left(\mathrm{kg} / \mathrm{m}^{2} / \mathrm{WHO}\right)\end{array}$ & $\begin{array}{l}\text { Total weight gain } \\
\text { in pregnancy (kg) }\end{array}$ & $\begin{array}{l}\text { Weight gain/week } \\
\text { in } 2 \text { nd and } 3 \text { rd } \\
\text { trimester* (kg) }\end{array}$ \\
\hline 18.5 & $12.5-18$ & $0.5-0.6$ \\
\hline $18.5-24.9$ & $11.5-16$ & $0.4-0.5$ \\
\hline $25.0-29.9$ & $7-11.5$ & $0.2-0.3$ \\
\hline$\geq 30$ & $5-9$ & $0.2-0.3$ \\
\hline
\end{tabular}

- Table 5 Blood glucose targets based on plasma-calibrated selftesting devices.

\begin{tabular}{|l|l|l|}
\hline Time & \multicolumn{2}{|l|}{ Plasma equivalent } \\
\hline & $\mathbf{m g} / \mathbf{d l}$ & $\mathbf{m m o l} / \mathbf{l}$ \\
\hline Fasting, preprandial & $65-95$ & $3.6-5.3$ \\
\hline 1 h postprandial & $<140$ & $<7.8$ \\
\hline 2 h postprandial & $<120$ & $<6.7$ \\
\hline
\end{tabular}

rameter in individual cases, e.g., non-compliance with blood glucose self-testing or doubtful quality of the measurements.

\section{Blood glucose targets}

- Table 5 shows the blood glucose control targets based on plasma-calibrated self-testing devices. There are no preferences for postprandial measurement after one or two hours, but the onehour levels correlate more with foetal growth and are more practical in ordinary life. Once a procedure is established, it is continued. The pregnant woman's initially limited experience with blood glucose measurement should be noted. Her self-testing results should as far as possible not be the sole criterion guiding therapy. The accuracy of the blood glucose tests done by the pregnant woman herself should be checked regularly in the treatment process. The target blood glucose levels are a guide and no detrimental effects for the child can be deduced from isolated instances of exceeding these targets.

\section{Insulin therapy}

\section{General indication for insulin therapy}

If the metabolic goals cannot be achieved by exhausting the lifestyle measures (dietary therapy, physical activity), insulin therapy is indicated. This is generally apparent within 2 weeks but can be necessary immediately or only in the course of the pregnancy, depending on the blood glucose levels. Fasting blood glucose levels $\geq 110 \mathrm{mg} / \mathrm{dl}$ ( $6.1 \mathrm{mmol} / \mathrm{l})$ can hardly be influenced by diet in pregnancy. Immediate insulin therapy should therefore be considered if repeated fasting blood glucose levels are $\geq 110 \mathrm{mg} / \mathrm{dl}$ (6.1 mmol/l). Roughly 20 to $30 \%$ of pregnant women with GDM require insulin. The indication for insulin therapy is reassessed continuously. Insulin therapy is indicated when $\geq 50 \%$ of self-mea- 
surements in the 4-point profiles within one week are above the target levels. This also applies when only $50 \%$ of the fasting glucose measurements in isolation are exceeded (start with basal insulin) or $50 \%$ of the postprandial levels after a meal, which more often affects breakfast (short-acting insulin). Before starting insulin therapy, correct adherence to dietary therapy should be reviewed. The indication should be examined carefully and strictly as insulin therapy has significant obstetric implications such as induction at term, in addition to the burden on the pregnant woman. Insulin therapy is usually started in an outpatient setting.

\section{Insulin therapy having regard to foetal growth on ultrasound}

The effects of maternal hyperglycaemia on the foetus differ individually and are associated with different risks depending on the growth pattern. When deciding on insulin therapy, therefore, the increase in foetal abdominal circumference (AC) should be taken into account by obtaining an ultrasound scan to assist the decision before starting the treatment (modified target level concept). Modification of the target blood glucose levels depending on the foetus's growth pattern should help to avoid both over- and undertreatment. When there is asymmetrical macrosomia with foetal $A C \geq 75$ th percentile, especially if there are other risk factors for foetal macrosomia (BMI $>30 \mathrm{~kg} / \mathrm{m}^{2}$, previous delivery of a LGA baby, fasting BG $>110 \mathrm{mg} / \mathrm{dl}$ in the day profile at the start of therapy), the attitude to starting insulin therapy should be more liberal and somewhat lower blood glucose targets should be aimed at. In the course of the pregnancy, the foetal growth parameters on ultrasound should also be considered when interpreting the blood glucose self-testing results and consequences for treatment. If foetal development is normosomic < 75th percentile of the AC, slightly exceeding the target levels can be tolerated and the indication for insulin should be considered more strictly.

\section{Special therapeutic questions}

\section{Isolated elevations of fasting glucose levels}

The fasting glucose level appears to have a major influence on neonatal complications, LGA and pre-eclampsia. After exercise and dietary therapy have been exhausted, insulin therapy should be started for isolated elevated fasting glucose levels when $>50 \%$ of the fasting glucose levels are above the applicable threshold of $95 \mathrm{mg} / \mathrm{dl}(5.3 \mathrm{mmol} / \mathrm{l})$.

\section{Late diagnosis of GDM - insulin therapy close to term}

It may be useful to start treatment with insulin even close to term to avoid neonatal hypoglycaemia.

\section{Unmasking a glucokinase gene mutation (GCK-MODY)}

In approximately $2 \%$ of all cases of impaired glucose tolerance in pregnancy, a glucokinase gene mutation (GCK-MODY, MODY 2) with autosomal dominant inheritance is unmasked. MODY-2 diabetes should be considered when the mother has persistent elevated fasting blood glucose levels of $99-144 \mathrm{mg} / \mathrm{dl}$ (5.5$8.8 \mathrm{mmol} / \mathrm{l})$, an only slight rise in blood glucose $<83 \mathrm{mg} / \mathrm{dl}$ $(<4.6 \mathrm{mmol} / \mathrm{l})$ in the oGTT, a normal or only slightly raised $\mathrm{HbA}_{1 \mathrm{c}}$ level and a positive family history of "mild" type 2 diabetes over 3 generations. A justified suspicion of a GCK-MODY diagnosis is confirmed by gene analysis (signed informed consent is required under the Genetic Diagnosis Act). Pregnant women with a fasting blood glucose level $>99 \mathrm{mg} / \mathrm{dl}(5.5 \mathrm{mmol} / \mathrm{l})$ in combination with a pre-conception $\mathrm{BMI}<25 \mathrm{~kg} / \mathrm{m}^{2}$ should be tested.

Only foetuses of pregnant women with the GCK mutation who are not carriers of the GCK mutation have an increased risk for macrosomia and subsequent complications of elevated maternal glucose during pregnancy. Insulin therapy should be initiated in pregnant women with GCK mutation only when disproportionate growth (AC $\geq 75$ th percentile) of the foetus is found on ultrasound.

\section{Insulin therapy procedure}

The indication for insulin should first be considered within 1-2 weeks after the start of basic therapy (diet, exercise) taking into account blood glucose self-testing, laboratory blood glucose tests and the biometric data of mother and foetus, and this should then be reviewed continually during the treatment process at the HCP's discretion. The insulin therapy should be in accordance with the ICT principle, but only basal or short-acting insulin may be necessary. If short-acting human insulins at adequate dosage cannot reduce postprandial blood glucose levels to target, a switch to insulin aspart or lispro should be considered. Both short- and long-acting insulin analogues can also be used initially. Insulin therapy should usually start in the outpatient setting and be reserved for diabetologists and perinatal physicians experienced in the care of diabetic pregnant women and with appropriate expertise.

\section{Oral antidiabetic drugs and GLP-1 analogues}

For pregnant women with GDM and suspected severe insulin resistance (insulin requirement $>1.5 \mathrm{lU} / \mathrm{kg}$ body weight) and when individually indicated, use of metformin can be considered following explanation of the off-label use. Medical contraindications must be investigated beforehand and laboratory parameters must be measured before the first dose of metformin, e.g., serum creatinine and creatinine clearance. A daily metformin dose of $2.0 \mathrm{~g}$ should not be exceeded. Sulphonylurea drugs should not be used during pregnancy. Alpha-glucosidase inhibitors, glitazones, glinides, DPP-4 inhibitors and GLP-1 analogues should not be prescribed for pregnant women with GDM because of the absence of authorisation, lack of experience and insufficient studies.

\section{Obstetric care}

Foetal monitoring

Foetal monitoring depends on additional risk factors and the severity of maternal hyperglycaemia.

\section{Ultrasonography}

\section{1st trimester}

When GDM is diagnosed before 14 weeks of gestation when there are additional risk factors (elevated blood glucose and $\mathrm{HbA}_{1 \mathrm{c}}$ levels, a history of cardiac malformation, obesity) or previous GDM, early detailed ultrasound organ diagnosis and echocardiography to exclude severe foetal malformations are indicated at $11+0-$ $13+6$ weeks. DEGUM stage II requirements must be met. 


\section{2nd trimester}

When GDM is diagnosed before 24 weeks of gestation when there are additional risk factors (elevated blood glucose and $\mathrm{HbA}_{1 \mathrm{c}}$ levels, a history of cardiac malformation, obesity), further detailed organ diagnosis and echocardiography of the foetus should take place at 19-22 weeks.

\section{3rd trimester}

Biometry is performed at 2- to 3-week intervals (AC percentiles), and at shorter intervals if there is an abnormal growth pattern (macrosomia, IUGR). Before delivery, the weight should be estimated and assessment of the ratio of abdomen and head is recommended (foetal macrosomia is a risk factor for shoulder dystocia). The thickness of the subcutaneous foetal fat can be included in the report.

\section{Doppler ultrasound}

The indications usual in all pregnancies apply. Doppler ultrasound scans are not indicated solely because of the GDM diagnosis.

\section{Cardiotocography (CTG)}

Dietary therapy: weekly CTG from 36 weeks of gestation, adjusting the frequency to the individual situation.

Insulin therapy: as in a pregnant woman with known type 1 diabetes pre-conception, according to the guideline on care of diabetic pregnant women (AWMF guideline 057/023), which recommends CTG from 32 weeks of gestation with the frequency adjusted to the individual situation.

\section{Antepartum monitoring of the mother}

Pre-eclampsia risk increased: intensive treatment of the GDM reduces the risk significantly.

Risk for intrauterine death (IUD) is increased if untreated or poor blood glucose control.

Premature birth (induction of foetal lung maturity, tocolysis)

Betamethasone for induction of foetal lung maturity (before $34+0$ weeks of gestation): blood glucose levels rise so must be strictly indicated. Adjust the insulin dose individually or initiate insulin treatment over a blood glucose level $\geq 200 \mathrm{mg} / \mathrm{dl}$ (11.1 mmol/l) or if there are hyperglycaemic symptoms.

Tocolysis should preferably be with an oxytocin or calcium antagonist and not with a beta-sympathomimetic (rise in maternal blood glucose, reinforced by concomitant bed rest).

\section{Birth planning}

\section{Choice of maternity clinic}

Pregnant women with GDM are risk patients.

GDM with dietary therapy: delivery in a maternity clinic with diabetological experience and attached neonatology should be advised.

GDM with insulin therapy: in compliance with guidelines the delivery must take place in a maternity clinic with attached neonatology (level 1 or 2 perinatal centre) to ensure optimal initial care of the child.

\section{Delivery timing, indication for induction}

Induction $<39+0$ weeks of gestation increases neonatal morbidity and transfer rate and should be avoided. Induction at $39+0$ $39+6$ weeks can be considered but is associated with a $50 \%$ increase in the induction rate and does not reduce neonatal morbidity. Premature (before $38+0$ ) induction because of poor blood glucose control is not desirable because of the morbidity associated with prematurity. Prenatal optimisation of blood glucose control is desirable. There is evidence that foetal morbidity in insulin-dependent GDM can be reduced by induction at 40 weeks and this should therefore be offered. With GDM and ultrasoundestimated foetal weight $>95$ th percentile, the possible benefits of induction after 37-0 weeks should be weighed against the effects of earlier gestational age at birth.

\section{Delivery by caesarean section}

When the estimated birth weight is $\geq 4500 \mathrm{~g}$, the risk of shoulder dystocia increases significantly and primary section should be recommended. Estimated weight 4,000-4,499 g: nuanced explanation of the individually increased risk of shoulder dystocia after foetal biometry, especially when there is a pronounced head-abdomen difference. However, the pregnant woman should be advised of the imprecision of the estimation, which increases with increasing birth weight, and be told of the risks of section and consequent impaired placental nidation in the next pregnancy.

\section{Pregnant women who have had bariatric surgery}

Pregnant women who have had bariatric surgery are regarded as risk patients and must be monitored closely obstetrically. Adequate replacement corresponding to the increased need must be ensured.

\section{Postpartum care}

Glucose monitoring of the mother during childbirth and in the puerperium

If labour is induced, short-acting insulins should be used for better controllability.

Blood glucose target in capillary plasma during childbirth: between 90 and $140 \mathrm{mg} / \mathrm{dl}$ (4.4-7.2 mmol/l).

Dietary therapy (well controlled): routine maternal blood glucose monitoring is not necessary during childbirth.

Insulin therapy: two-hourly measurement of blood glucose levels in insulin-treated GDM, adjusting the intervals individually; in GDM, insulin is rarely needed during childbirth. The insulin therapy is stopped post partum. Further monitoring is by a 4-point daily profile on the 2 nd day postpartum and the treating diabetologist is informed if levels are high repeatedly. The thresholds are the same as those in non-pregnant women. Insulin is indicated post partum if blood glucose levels $\geq 200 \mathrm{mg} / \mathrm{dl}(11.1 \mathrm{mmol} / \mathrm{l})$ or if there are hyperglycaemic symptoms.

\section{Maternal follow-up}

The impaired glucose tolerance does not resolve after pregnancy in approximately $13-40 \%$ of cases. Women have a $7-8$-fold increased risk of diabetes after GDM. The risk is particularly elevated in the event of pre-conception obesity, positive family history of 
diabetes mellitus, GDM requiring insulin, greater age, Asian women and black African women.

\section{Postpartum 75-g oGTT}

Normal blood glucose levels post partum: 75-g oGTT 6-12 weeks after delivery independent of breast-feeding. Normal values for the oGTT outside the pregnancy apply, with blood glucose measurements in venous plasma fasting and 2 hours after the glucose load according to WHO guidelines:

- normal: fasting < $100 \mathrm{mg} / \mathrm{dl} \quad(5.6 \mathrm{mmol} / \mathrm{l})$, < $140 \mathrm{mg} / \mathrm{dl}$ (7.8 mmol/l) $2 \mathrm{~h}$ after loading;

- diabetes mellitus: fasting $\geq 126 \mathrm{mg} / \mathrm{dl}$ ( $7.0 \mathrm{mmol} / \mathrm{l})$ and/or $\geq 200 \mathrm{mg} / \mathrm{dl}$ (11.1 mmol/l) $2 \mathrm{~h}$ after loading;

- abnormal fasting glucose (IFG): 100-125 mg/dl (5.6$6.9 \mathrm{mmol} / \mathrm{l})$;

- impaired glucose tolerance after 2 h (IGT): 140-199 mg/l (7.8$11.05 \mathrm{mmol} / \mathrm{l})$.

Primary measurement of the $\mathrm{HbA}_{1 \mathrm{c}}$ level 6-12 weeks post partum is not recommended for diagnosis, and fasting glucose alone is also insufficient. If glucose tolerance is impaired or there are other risk factors such as pre-conception obesity or insulin therapy of the GDM, women should be counselled intensively about lifestyle measures to reduce the risk of conversion to overt diabetes.

\section{Other postpartum tests}

The increased risk for women with GDM to develop diabetes in the first 10 years requires continuous follow-up with monitoring of glucose metabolism. The rules for diabetes diagnosis of the guidelines of the German Diabetes Association, Therapy of type 2 diabetes, p. 29-32, usually with a fasting glucose and $\mathrm{HbA}_{1 \mathrm{c}}$, and oGTT if necessary every 2 years. With a postprandial diagnosis of IGT/IFT, annual oGTT should be done. When planning pregnancy, diabetes diagnostic testing should take place with $\mathrm{HbA}_{1 \mathrm{c}}$ and fasting glucose at least. Early testing for hyperglycaemia should be performed in the 1st trimester (first consultation) according to the existing guideline in every further pregnancy. If development of type 1 diabetes is suspected (women with $\mathrm{BMI}<30 \mathrm{~kg} / \mathrm{m}^{2}$ and insulin therapy of the GDM), autoantibody screening should be done (e.g., anti-GAD, anti-IA2, anti-ICA and anti-ZnT8).

\section{Peripartum depression}

Compared with glucose-tolerant pregnant women, the rate of postpartum depression is up to twice as high in women with GDM, especially in those from a socially disadvantaged background. The Edinburgh Postnatal Depression Scale (EPDS) is a suitable instrument for detecting the presence of postpartum depression. According to this, all EPDS scores of at least 10 point to a depressive mood. If this is suspected, it should receive further specialist investigation so timely treatment can be initiated. A suitable time for using the postnatal depression scale is the oGTT timeframe 6-12 weeks after pregnancy.

\section{Diabetes prevention}

Women have a 7-8-fold increased diabetes risk after GDM. Lifestyle modication is regarded as the priority measure. Women with impaired glucose tolerance after GDM benefit from lifestyle changes to prevent diabetes-induced and macroangiopathic complications. They are advised and instructed on maintaining a diet tailored to their needs, normalising weight, smoking cessation training where applicable, and regular physical activity. This can reduce diabetes manifestation by $50 \%$ in 3 years and by $35 \%$ in 10 years. In addition, women who have not yet completed their families should be advised of the risks of unplanned pregnancy with diabetes.

\section{Breast-feeding}

Mothers after GDM breast-feed their children more seldom and more briefly than women without diabetes, especially in the case of overweight and obesity, insulin-treated GDM and lower educational level. Mothers with GDM breast-feed more successfully if they receive breast-feeding advice before delivery and avail of medical care postnatally from non-physicians as well as doctors.

\section{Breast-feeding and effects on the mother's health}

Breast-feeding has short-term positive effects on maternal metabolism (improvement in glucose homeostasis, insulin sensitivity and parameters of fat metabolism), and breast-feeding in addition appears to markedly reduce the risk for type 2 diabetes and metabolic syndrome in mothers with GDM up to 15 years after delivery.

\section{Breast-feeding and effects on the child's health}

No or shorter breast-feeding ( $<3$ months) is associated with later overweight of the children, especially in the case of children of obese gestational diabetics.

Women with GDM should therefore be strongly encouraged to breast-feed their children. Obese pregnant women with GDM in particular should be motivated and assisted to breast-feed. Recommendation: all pregnant women with GDM should be advised of the benefits of breast-feeding for mother and child even before delivery and strategies for a successful start of breast-feeding should be outlined. Exclusive breast-feeding should be for at least 4-6 months. Even after the introduction of supplementary feeds - at the start of the 5th month at the earliest and the start of the 7th month at the latest - babies should continue to be breast-fed as long as possible.

\section{Conflict of Interest}

See long version: https://www.awmf.org/fileadmin/user_upload/ Leitlinien/057_D_Diabetes_Ges/057-008i_S3_Gestationsdiabetesmellitus-GDM-Diagnostik-Therapie-Nachsorge_2018-03.pdf

References

The references can be viewed in the full version of the guideline at http://www.awmf.org/leitlinien/detail/II/057-008.html 


\section{Guideline Program}

\section{Editors}

Leading Professional Medical Associations

\section{Ty}

German Society of Gynecology and Obstetrics (Deutsche Gesellschaft für Gynäkologie und Geburtshilfe e. V. [DGGG])

Head Office of DGGG and Professional Societies Hausvogteiplatz 12, DE-10117 Berlin info@dggg.de

http://www.dggg.de/

\section{President of DGGG}

Prof. Dr. med. Anton Scharl

Direktor der Frauenkliniken

Klinikum St. Marien Amberg

Mariahilfbergweg 7, DE-92224 Amberg

Kliniken Nordoberpfalz AG

Söllnerstraße 16, DE-92637 Weiden

\section{DGGG Guidelines Representatives}

Prof. Dr. med. Matthias W. Beckmann Universitätsklinikum Erlangen, Frauenklinik Universitätsstraße 21-23, DE-91054 Erlangen

Prof. Dr. med. Erich-Franz Solomayer Universitätsklinikum des Saarlandes Geburtshilfe und Reproduktionsmedizin Kirrberger Straße, Gebäude 9, DE-66421 Homburg

\section{Guidelines Coordination}

Dr. med. Paul Gaß, Dr. med. Gregor Olmes, Christina Meixner Universitätsklinikum Erlangen, Frauenklinik Universitätsstraße 21-23, DE-91054 Erlangen fk-dggg-leitlinien@uk-erlangen.de http://www.dggg.de/leitlinienstellungnahmen

\section{OEGGG}

Austrian Society of Gynecology and Obstetrics (Österreichische Gesellschaft für Gynäkologie und Geburtshilfe [OEGGG])

Frankgasse 8, AT-1090 Wien

stephanie.leutgeb@oeggg.at

http://www.oeggg.at

\section{President of OEGGG}

Prof. Dr. med. Petra Kohlberger

Universitätsklinik für Frauenheilkunde Wien

Währinger Gürtel 18-20, AT-1090 Wien

\section{OEGGG Guidelines Representatives}

Prof. Dr. med. Karl Tamussino

Universitätsklinik für Frauenheilkunde und Geburtshilfe Graz Auenbruggerplatz 14, AT-8036 Graz

Prof. Dr. med. Hanns Helmer Universitätsklinik für Frauenheilkunde Wien Währinger Gürtel 18-20, AT-1090 Wien

\section{gynécologie}

Swiss Society of Gynecology and Obstetrics (Schweizerische Gesellschaft für Gynäkologie und Geburtshilfe [SGGG])

Gynécologie Suisse SGGG Altenbergstraße 29, Postfach 6, CH-3000 Bern 8 sekretariat@sggg.ch http://www.sggg.ch/

\section{President of SGGG}

Dr. med. David Ehm

FMH für Geburtshilfe und Gynäkologie Nägeligasse 13, CH-3011 Bern

\section{SGGG Guidelines Representatives}

Prof. Dr. med. Daniel Surbek Universitätsklinik für Frauenheilkunde Geburtshilfe und feto-maternale Medizin Inselspital Bern Effingerstraße 102, CH-3010 Bern

Prof. Dr. med. René Hornung Kantonsspital St. Gallen, Frauenklinik Rorschacher Straße 95, CH-9007 St. Gallen 